\title{
O FUTEBOL OPERÁRIO E A CONSTRUÇÃO DO ESTÁDIO MUNICIPAL “PACAEMBU”
}

Matheus Barrientos Ferreira

UNOESTE - Universidade do Oeste Paulista, Graduado em História, Presidente Prudente-SP, E-mail: matheusbr65@hotmail.com,

\section{RESUMO}

A presente pesquisa tem como propósito o estudo da história da construção do Estádio Municipal do Pacaembu, na cidade de São Paulo, abordando o início do futebol paulista desde suas raízes e sua evolução, o recorte temporal selecionado foi o período de 1900-1940. A reflexão do trabalho se embasará no propósito de analisar o processo de desenvolvimento do futebol dentro da capital paulista e em outras localidades do país que tiveram influência para o desenvolvimento do futebol no Brasil.

Palavras-chave: História do Brasil, Futebol, São Paulo, Era Vargas, Pacaembu.

THE WORKFORCE FOOTBALL AND THE CONSTRUCTION OF THE "PACAEMBU" MUNICIPAL STADIUM.

\begin{abstract}
The purpose of this research is to study the history of the construction of the Pacaembu Municipal Stadium, in the city of São Paulo, focusing on the beginning of São Paulo football since the origin and evolution, in a temporal cut of 1900-1940. The reflection of the work will be based on the purpose of analyzing the development process of soccer within the city of São Paulo and in other localities of the country that had influence for the development of soccer in Brazil.
\end{abstract}

Keyword: History of Brazil, Football, São Paulo, It was Vargas, Pacaembu. 


\section{INTRODUÇÃO}

O autor Alfredo Oscar Salun ${ }^{1}$ em seu pensamento sobre a introdução do futebol na sociedade brasileira relata o seguinte pensamento:

A origem do futebol no Brasil também é tema de discussão, na medida em que são apontadas diferentes trajetórias: a primeira e mais conhecida é a versão oficializadora que consta nos anais da Confederação Brasileira de Futebol e da Federação Paulista de Futebol, que considera Charles Miller o introdutor desse esporte no País. ${ }^{2}$

A historiografia em seu processo de construção da história do futebol brasileiro, mostra duas vertentes na linha de pensamento sobre a legitimidade de Charles Miller, e sua introdução do futebol aos brasileiros, uma questão crítica, Miller chega ao Brasil com os utensílios necessários para a prática, isso pode se afirmar através do relato do autor Wilson Roberto Gambeta, que diz:

Charles Miller desembarcou no porto de Santos, em Novembro de 1894, trazendo na bagagem duas bolas de couro, uma bomba de ar para enchê-las, um par de chuteiras, duas camisas de times que ele defendera na Inglaterra e um livro de regras do associationfootball. ${ }^{3}$

Estudos sobre a introdução do futebol demonstram que sua fuga para fora dos muros dos colégios da elite paulistana para a prática do esporte e a formação das primeiras associações desportivas, que o popularizou na capital paulistana.

A elite paulistana foi a primeira a criar associações em prol do futebol, uma união de pessoas com interesses em praticar a modalidade e defender as cores de um time que os representaria dentro das quatro linhas ${ }^{4}$. Segundo o autor Waldenyr Caldas, o futebol era uma tradição passada de pai para filho no início do século XX, como o próprio autor diz: "Por se tratar de um esporte elitizado, que dava status, os próprios pais de alunos faziam um tipo de pressão para que os colégios incluíssem o futebol nas práticas esportivas." ${ }^{5}$

O objetivo deste estudo foi análise da inserção do futebol em terras brasileiras, posteriormente acompanhando o desenvolvimento da pratica dentro da capital paulista desde a elite até a classe operária. O ponto alvo do meu artigo é o surgimento e desenvolvimento do futebol operário e em um segundo plano a construção do Estádio Municipal do Pacaembu em São Paulo. Analisar as circunstâncias da construção do estádio do Pacaembu e sua utilização por Getúlio Vargas. Como cenário para os atos políticos.

\section{METODOLOGIA}

A presente pesquisa tem por objetivo analisar e complementar a história da construção do Estádio Municipal Paulo Machado de Carvalho "Pacaembu", sendo uma pesquisa aprofundada.

A metodologia de trabalho será direcionada por um recorte temporal entre o período de 1900-1940, será uma pesquisa de caráter bibliográfico e documental embasada em livros, artigos, jornais da época e teses acadêmicas, a pesquisa com fontes documentais se realizará no acervo do Museu do Futebol disponível no próprio site do Museu do Futebol.

As fontes, no caso os jornais selecionados foram: O Estado de São Paulo, Correio Paulistano e O Comércio de São Paulo, serão acessados digitalmente, através do CEDAP (Centro de Desenvolvimento e Apoio à Pesquisa) da Unesp (Campus Assis) e no próprio acervo digital dos jornais.

\footnotetext{
${ }^{1}$ Alfredo Oscar Salun, traz em sua tese para obtenção do título de Doutor, dois pensamentos de seguimentos de direção oposta sobre como foi introduzido o futebol no Brasil, de um lado Charles Miller e seus ensinamentos britânicos e em outra direção o futebol já existente antes de Charles Miller.

${ }^{2}$ OSCAR, Alfredo Salun, Palestra Itália e Corinthians: quinta coluna ou tudo buonagente?. São Paulo, USP, 2007.

${ }^{3}$ ROBERTO, Wilson Gambeta, A bola rolou - O Velódromo Paulista e os espetáculos de futebol 1895 - 1916. São Paulo, USP, 2013.

${ }^{4}$ Quatro linhas, apelido dado ao futebol pela modalidade ser disputada dentro de um campo em formato de retângulo.

${ }^{5}$ CALDAS, Waldenyr, Aspectos sociopolíticos do futebol brasileiro. São Paulo. Revista USP 22, 1994.p.42.
} 
Em um segundo momento serão utilizadas fontes iconográficas como fotografias e imagens que ilustrem o recorte temporal que estará sendo analisado.

Serão analisadas criticamente as informações para reconstituir o período da construção do Estádio Municipal buscando perceber questões relevantes para o entendimento da sua importância na realidade social.

\section{RESULTADOS}

A pesquisa nos levou a compreender a transformação da prática do futebol no Brasil, inicialmente de caráter elitista e segregacionista, restrito apenas a tradicional sociedade paulistana a seu apogeu como esporte nacional. Para tal a mesma discorreu sobre a forma da popularização do esporte nos meios operários e a criação das associações que antecederam a formação dos clubes operários. Essas significativas alterações da prática esportiva dentro da capital paulista proporcionou mudanças conjunturais e estruturais no esporte e suas relações com a sociedade, passando de um esporte elitista para se tornar a paixão nacional. $O$ futebol largamente praticado na cidade reforçou as práticas de lazer e integração na classe operária.

A manutenção de equipes de futebol que promoviam atividades sociais, como os bailes, excursões, piqueniques e pescarias integrou as famílias, sendo um diferencial para a sociabilidade urbana.

A paixão pelo esporte foi decisiva para a construção da magnífica obra do Estádio Municipal do Pacaembu pelo governo Vargas a fim de abrigar o esporte e popularizar-se perante a classe trabalhadora.

\section{DISCUSSÃO}

A discussão será em fontes escritas sobre o desenvolvimento do futebol operário na capital paulista, abordando as dificuldades de consolidação e expansão do esporte fora do meio das camadas mais ricas da cidade. O lado elitista do esporte restringia a sua difusão no meio da camada mais empobrecida como prática esportiva na cidade de São Paulo. A pesquisa realiza uma análise da incorporação e difusão do esporte nas camadas populares, principalmente no meio operário. A paixão que o futebol despertou na sociedade e seu papel de aglutinador social fizeram com que sua popularidade fosse determinante para a construção do Estádio Municipal do Pacaembu, cuja obra pretendia promover e identidade cívica da população com a representatividade do governo Vargas.

\section{CONCLUSÃO}

O futebol era maior que as paredes das fabricas, saiu de controle, saiu do pequeno campo para toda a cidade, era a alma, a dignidade e a luta de cada trabalhador, ganhou representatividade para todos, era uma espécie de união sem palavra, mas sim com gestos, a necessidade de criação da sua própria identidade fez com que os operários coloca-se de lado o time de suas fabricas, mesmo com todo apoio e foi em busca das raízes daquilo que gerava esperança a cada chute. Assim surgem os times pequenos de bairro de cada operário, fomentado pela paixão e pela esperança.

No entanto o futebol era questão disputa fora dos campos, a disputa dentro da campo era deixada apenas para o espetáculo, e fora das "quarto linhas" o embate sobre o controle da modalidade e a diferenciação da prática da elite e da diversão assim chamada do operário, mesmo com todo evolucionismo do futebol dentro da capital paulista, ainda tínhamos a predominância da tentativa de separação da elite, na tentativa de oprimir e rebaixar a prática operária, que ela mesmo a elite tinha proporcionado respaldo para seu desenvolvimento, dentro e fora de campo. 
A construção do Estádio Municipal do Pacaembu, é a construção que ao mesmo tempo que atendia a necessidade da capital de paulista de necessidade de um palco para o tamanho de seu espetáculo ao finais de semana, também era a organização na tentativa de obter todos sobre suas "mãos", como queria Getúlio Vargas.

\section{REFERÊNCIAS}

CALDAS, Waldenir, Aspectos sociopolíticos do futebol brasileiro. São Paulo, Revista USP 22, 1994. DA MATTA, Roberto (Org.). Universo do futebol: esporte e sociedade brasileira. Rio de Janeiro: Pinakotheke, 1982.

DUARTE, René Gonçalvez Junior, Friedenreich e a reinvenção de São Paulo: o futebol e a vitória na fundação da metrópole. São Paulo. USP, 2008.

ENRIQUE, Miguel Stédile, Clubes de futebol operário como espaço de autonomia e dominação. Cascavel. UNIOESTE, 2014.

FERNANDO, João Ferreira, A construção do Pacaembu, São Paulo: Paz e Terra, 2008.

FRANCO JÚNIOR, Hilário. A Dança dos deuses: futebol, sociedade, cultura. São Paulo. Companhia das Letras, 2007.

FRANÇA, João Paulo Streapco, Tese "Cego é aquele que só vê a bola." O futebol em São Paulo e a formação das principais equipes paulistanas: S. C. Corinthians Paulista, S. E. Palmeiras e São Paulo F. C. (1894 - 1942). São Paulo, USP, 2010.

FRANZINI, Fábio. Corações na ponta da chuteira: capítulos iniciais da história do futebol brasileiro (1919-1938).São Paulo. DP\&A Editora, 2003.

JOSÉ, Plínio Labriola de Campos Negreiros, Futebol nos anos 1930 e 1940: construindo a identidade nacional. Curitiba. UFPR, 2003.

MARTIN, Fatima Rodrigues Ferreira Antunes, Futebol de Fábrica em São Paulo. São Paulo USP, 1992.

MARTIN, Fatima Rodrigues Ferreira Antunes. O futebol nas fábricas. Revista USP, São Paulo (dossiê futebol), num 22, jun/jul/ago de 1994.

MAZZONI, Thomaz,História do futebol no Brasil: 1894-1950. São Paulo. USP, 1950.

OSCAR, Alfredo Slun, Tese Palestra Itália e Corinthians: quinta coluna ou tudo buonagente?. São Paulo USP, 2007.

PEREIRA, Marvio Leoncini, Entendo o negócio futebol: um estudo sobre a transformação do modelo de gestão estratégica nos clubes de futebol. São Paulo. USP, 2001.

PRONI, Marcelo Weishaupt. A metamorfose do futebol. Campinas- SP. Unicamp, Instituto de Economia, 2000.

RIBIEIRO, N.B. et all. Pedreira Prado Lopes: Becos da memória, desenhos da cidade. A vila no trajeto de sua história oral. Belo Horizonte, UNI-BH, 2001. 
ROBERTO, Wilson Gambeta, A bola rolou - O Velódromo Paulista e os espetáculos de futebol 1895 - 1916. São Paulo, USP, 2013.

STEINER, Marcelo Giglio de Oliveira, Arquitetura em São Paulo na Era Vargas. O art déco e a arquitetura fascista nos edifícios públicos (1930-1945), São Paulo: 2008.

YAGUINUMA, Thiago Peruchi, Tese Futebol : introdução, popularização e a participação do negro no esporte bretão (1900-1933). São Paulo. Unoeste, 20015.

FONTES - JORNAIS.

- O Estado de São Paulo.

- Correio Paulistano.

- O Comércio de São Paulo. 